\title{
Decomposing complex traits through crop modelling to support cultivar recommendation. A proof of concept with a focus on phenology and field pea
}

\author{
Livia Paleari, ${ }^{1}$ Ermes Movedi, ${ }^{1}$ Fosco M. Vesely, ${ }^{1}$ Matteo Tettamanti, ${ }^{1}$ Daniele Piva, ${ }^{2}$ \\ Roberto Confalonieri ${ }^{1}$ \\ ${ }^{1}$ University of Milano, ESP, Cassandra lab, Milano; ${ }^{2}$ Conserve Italia Soc. Coop. Agricola, San Lazzaro di \\ Savena (BO), Italy
}

\begin{abstract}
Highlights
- Crop models are powerful tools to support cultivar choice by exploring genotype $\times$ environment $\times$ management interactions.

- Crop models require cultivar-specific phenotyping data at the level of functional traits.

- We propose a methodology that uses data routinely collected in operational contexts to derive functional trait values.

- This study is a proof of concept of how to increase the applicability of model-based approaches for cultivar choice.
\end{abstract}

\begin{abstract}
Cultivar recommendation is crucial for achieving high and stable yields, and crop models can successfully support it because of their capability of exploring genotype $\times$ environment $\times$ management interactions. Different modelling approaches have been developed to this end, primarily relying on dedicated field trials to
\end{abstract}

Correspondence: Livia Paleari, University of Milano, ESP, Cassandra lab, via Celoria 2, 20133 Milano, Italy. Tel.: +39.02.50316578.

E-mail: livia.paleari@unimi.it ; roberto.confalonieri@unimi.it

Key words: WOFOST-GT2; Pisum sativum L.; E-FAST; sensitivity analysis; ideotype; cultivar recommendation.

Acknowledgements: this project was partly funded by the EmiliaRomagna Region, grant number FEASR PSR 2014-2020 sottomisura 16.1.01, domanda 5004939, and grant number FEASR PSR 2014-2020 sottomisura 16.2.01, domanda 5049726. Furthermore, we gratefully acknowledged Dr. Francesco Bergonzi and Dr. Giacomo Zibordi (Conserve Italia Soc. Coop. Agricola) for providing management and phenological data, as well as precious feedback on results.

Conflict of interest: the authors declare no conflict of interest.

See online Appendix for supplementary Figures and Tables.

Received for publication: 26 October 2021.

Revision received: 15 December 2021.

Accepted for publication: 7 January 2022.

${ }^{C}$ Copyright: the Author(s), 2022

Licensee PAGEPress, Italy

Italian Journal of Agronomy 2022; 17:1998

doi:10.4081/ija.2022.1998

This article is distributed under the terms of the Creative Commons Attribution Noncommercial License (by-nc 4.0) which permits any noncommercial use, distribution, and reproduction in any medium, provided the original author(s) and source are credited. characterize the germplasm of interest. Here, we show how even data routinely collected in operational contexts can be used for model-based cultivar recommendation, with a case study on phenological traits and field pea (Pisum sativum L.).

Eight hundred and four datasets, including days from sowing to plant emergence, first flower, and maturity, were collected in Northern Italy from 2017 to 2020, and they were used to optimise six parameters (base, optimum, and maximum temperature for development, growing degree days to reach emergence, flowering, and maturity) of the crop model WOFOST-GT2 for 13 cultivars. This allowed obtaining the phenotypic profiles for these cultivars at the level of the functional trait, without the need of carrying out dedicated phenotypisations. Sensitivity analysis (SA) techniques (E-FAST) and the statistical distributions of the optimised parameters were used to design pea ideotypes able to maximise yields and yield stability in 24 agro-climatic contexts (three soil conditions $\times$ two sowing times $\times$ four agro-climatic classes). For each context, the 13 cultivars were ranked according to their similarity to the ideotype based on the weighted Euclidean distance. Results of SA identified growing degree days to reach flowering as the trait mainly affecting crop productivity, although cardinal temperatures also played a role, especially in the case of early sowings. This is reflected in the ideotypes and, therefore, in cultivar ranking, leading to recommend a panel of cultivars characterised by low base temperature and high thermal requirements to reach flowering. Despite the limits of the study, which is focused only on phenological traits, it represents an extension of available approaches for model-aided cultivar recommendation, given that the methodology we propose can take full advantage of the potentialities of crop models without requiring dedicated experiments aimed at profiling the germplasm of interest at the level of functional traits.

\section{Introduction}

Since the early years of their development, one of the main targets for crop models has been field decision-making to optimise crop management (van Keulen and Wolf, 1986). Using parameters representing species- and genotype-specific morpho-physiologi- 
cal features and variables related to weather, soil, and management practices, crop models successfully reproduce crop growth and development as a function of genotypic, environmental, and management factors. Despite being a simplification of real cropping systems, their potential application to an extremely wide range of agro-climatic conditions makes crop models a valuable support tool for analysing genotype by environment interactions (Hammer et al., 2002) and, thus, to predict cultivar performance under various conditions (Jeuffroy et al., 2014). Cultivar choice is one of the most important aspects of crop management, since identifying the most suitable cultivar for a given environmental condition is a prerequisite for achieving high and stable yields (Annicchiarico, 2002). Classical approaches for cultivar recommendation are based on field trials conducted during multiple seasons and at different sites to explore the genotypic performance while accounting for the environmental variability expected in the cultivation area. However, the complexity of genotype $(\mathrm{G})$ by environment $(\mathrm{E})$ by management $(\mathrm{M})$ interactions may hamper the evaluation of cultivar performance because it can cause a re-ranking of cultivars as the environment changes (Lecomte et al., 2010). An extensive and thorough sampling of the explored environments is, therefore, crucial to get reliable results. However, the availability of resources often limits the size of the sample of environments. This is why crop modelling has been identified as a technology that can give a valuable contribution for extending the considerations that can be drawn from field trials (Jeuffroy et al., 2014).

Different approaches have been developed to integrate crop models in cultivar recommendation frameworks. By focusing the analysis at farm level and on-field pea as a case study, Jeuffroy et al. (2012) showed how the variability in growing conditions including that induced by constraints to fieldwork organisation can be successfully explored via crop modelling, leading to alternative rankings of genotypes according to farm characteristics. This farm-to-farm variability in terms of the most suitable genotype cannot be accounted for by conventional cultivar evaluation trials, highlighting the added value provided by crop simulations. Casadebaig et al. (2016) used a sunflower model and dedicated plant phenotyping from multi-environment trials to derive genotype-specific model parameters, in turn, used to define the best combinations of cultivar, environment, and management practices. The study underlined the advantages of analysing local adaptation when addressing cultivar recommendations (Casadebaig et al., 2016). More recently, Paleari et al. (2020) proposed to support cultivar recommendation by analysing the similarities between the model-derived ideotypes defined for specific soil, climate, and management conditions and the functional trait profiles (Violle et al., 2007) of available cultivars. The underlying assumption is that, given that the ideotype represents the optimal combination of functional traits to maximize the objective function in a given environment, the cultivar(s) most similar to this ideal combination of traits is the best choice for the same environment. As shown by Paleari et al. (2020), the functional traits of interest can be measured in trials carried out at a few locations, given that functional traits are only lightly affected by $\mathrm{G} \times \mathrm{E} \times \mathrm{M}$ interactions. The latter are then accounted for by the model while simulating performance traits (e.g., yield) under various conditions, with performance traits being emergent properties of the modelled system derived by explicitly considering the effect of environmental and management drivers (Hammer et al., 2005). For example, maximum radiation use efficiency (RUE, gr $\mathrm{MJ}^{-1}$ ) is a genotype-specific model parameter (corresponding to a plant functional trait). In contrast, aboveground biomass is a variable resulting from the interaction between the genotype and the environment that can affect RUE through, e.g., limitations due to unfavourable temperatures, excess radiation, drought, nutrient deficiencies, and diseases.

However, some of the key functional traits for adaptation to the target area of cultivation can hardly be measured under field conditions and for multiple genotypes. A clear example is traits dealing with the response to temperature, whose evaluation requires dedicated experimental trials under controlled conditions (e.g., Boote et al., 2018). Attempts have been made to use crop models and optimization algorithms to support phenotyping for traits that are hard to be quantified experimentally (Olivier and Annandale, 1998; Luquet et al., 2006; Martre et al., 2015; Onogi et al., 2016; Messina et al., 2018). This provides a promising approach to extend the range of functional traits considered in model-aided cultivar evaluation and recommendation.

Focusing on field pea and phenology, this study aims to show how the Paleari et al. (2020) approach can be extended by using optimisation algorithms to derive functional traits profiles of multiple cultivars from data routinely collected under operational farming conditions. The final goal is to increase the applicability of model-aided methodologies to support cultivar recommendation.

\section{Materials and methods}

The methodology adopted in this study for cultivar recommendation extends the one proposed by Paleari et al. (2020), which is based on the following steps (Figure 1): i) characterising the available germplasm for the functional traits of interest; ii) deriving distributions of functional traits; iii) classifying the target cultivation area in homogeneous contexts according to the soil, climate and management factors; iv) using the distributions derived in step ii

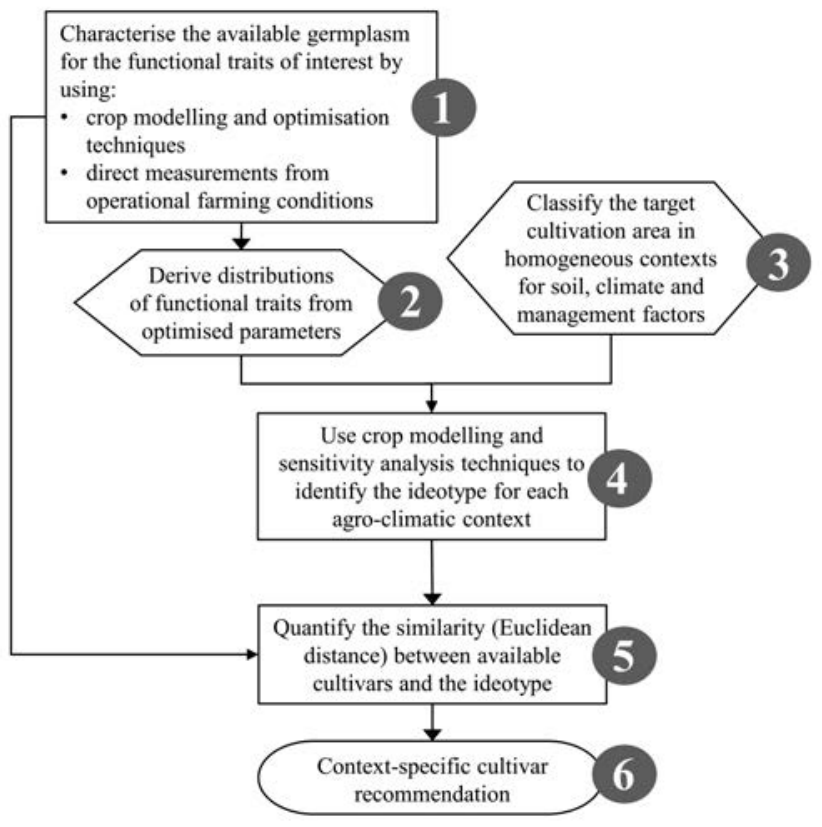

Figure 1. Flowchart of the methodology used for supporting cultivar recommendation. The methodology, originally proposed by Paleari et al. (2020), has been extended in this study to allow using data routinely collected in operational contexts for deriving functional traits through crop modelling and optimisation algorithms (step 1). 
and sensitivity analysis techniques to identify the ideal plant type (i.e., the ideotype) for each of the contexts defined in step (iii); v) for each context, looking for the cultivar - among those available that is more similar to the ideotype, i.e., vi) the cultivar recommended for that context. Step $i$, $i i$, and $v$ require that available cultivars are characterised for the functional traits corresponding to the parameters of the crop model, and - in the original approach from Paleari et al. (2020) - this requires dedicated experiments. In this study, functional trait values (dealing with the phenological response to photoperiod and temperature) were instead derived by decomposing complex ones (e.g., days to the first flower routinely determined in operational farming conditions) using optimisation techniques, analogously to what is done in crop model-aided genomic prediction studies (e.g., Onogi et al., 2016; Messina et al., 2018). Technical details for each of the steps are provided in the following sections.

\section{Crop model and parameterisation for field pea}

The generic crop model WOFOST-GT2 (Stella et al., 2014) was used, which extends the original WOFOST version (van Keulen and Wolf, 1986). Thermal time accumulation is derived from mean air daily temperature and a beta response function driven by the parameters' base, optimum and maximum temperature. Daily-cumulated thermal time is further corrected to account for day length by applying a photoperiod factor (0 to 1$)$. Phenological stages are accomplished when thermal time is equal to - or higher than - the corresponding requirements (e.g., growing degree days needed to reach emergence, flowering, and maturity). Photosynthesis is simulated by integrating the instantaneous gross $\mathrm{CO}_{2}$ assimilations estimated at three moments during the day and at multiple canopy depths as a function of intercepted radiation and a leaf light response curve. Net biomass accumulation is then derived by subtracting the growth and maintenance respiration, in turn, estimated from the dry weight of plant organs, the partitioning of photosynthates to plant organs in the day, and from mean daily air temperature. Light interception is estimated as a function of global solar radiation, leaf area index (LAI), and leaf angle distribution. To account for the variability in irradiance level along the vertical profile, direct and diffuse radiation are estimated at several horizontal canopy layers that increase during the crop cycle until full canopy development. LAI expansion is derived as a function of temperature at early crop stages and as a function of a development-dependent specific leaf area (SLA) and later partitioning to leaves. Photosynthetically active (green) LAI is estimated by subtracting from the total LAI the dead LAI units, which are daily computed as a function of self-shading and leaf senescence.

The species-specific parameterisation of WOFOST-GT2 for field pea was derived by using the datasets described in detail by Ravasi et al. (2020), including aboveground biomass, LAI, phenology, pod biomass, and yield data collected in seven field trials conducted in Northern Italy during 2016 and 2017. A summary of the datasets is reported in Table S1. Agreement between observed and simulated variables was evaluated by using four metrics: NashSutcliffe modelling efficiency (EF, from $-\infty$ to 1, optimum 1; Nash and Sutcliffe, 1970), mean absolute error (MAE, from 0 to $+\infty$, optimum 0 ), relative root mean square error (RRMSE, from 0 to $+\infty$, optimum 0; Jørgensen et al., 1986), and coefficient of determination $\left(\mathrm{R}^{2}\right)$ of the linear regression between simulated data and observations.

\section{Decomposition of complex traits via optimisation}

Phenological data were made available by Conserve Italia Soc.
Coop. Agricola, is one of the major European companies in the sector of preserved fruit and vegetable foods. The data refer to 804 datasets with observations of days from sowing to harvest collected in Northern Italy from 2017 to 2020 (Figure 2). Additional data on plant emergence [code 09 of the Biologische Bundesanstalt, Bundessortenamt und Chemische Industrie (BBCH scale for pea; Meier, 2001)] and first flower appearance (BBCH 60) were also available, respectively, for 683 and 637 datasets out of 804 . Overall, the database included phenological observations for 13 pea cultivars. When possible, cultivars for which few observations were available were grouped according to similarities in the observed length of their phenological phases under different conditions for soil and climate. This allowed minimising the risk of losing robustness because of unfavourable relationships between the number of observations and the number of parameters to optimise. This led to eight cultivars that were considered singularly and two groups of cultivars (Table S2). Given all data referred to green pea grown for the processed pea industry, harvest occurred at $\mathrm{BBCH}$ codes 76 or 77 , which correspond to tenderometer values ranging from 120 to 130 .

Weather data were retrieved from the weather service of the University of Milan Cassandra Lab (www.cassandralab.com), providing historical, near real-time, and forecasted daily weather data at $0.016^{\circ} \times 0.016^{\circ}$ resolution for the whole European area since $1^{\text {st }}$ January 2000 . Rough data gathered from the international networks of NOAA-GSOD (NOAA, 2020a), METAR (NOAA, 2020b), and SYNOP (NOAA, 2020c) and several regional extension and environmental services are spatially downscaled using dedicated geostatistical techniques and modelling tools (Mariani et al., 2012, 2016; Cola et al., 2020) accounting for elevation (USGS Gtopo30; USGS, 2020). Reference evapotranspiration is estimated using the Penman-Monteith method (Allen et al., 1998).

For each of the eight cultivars and the two cultivar groups, the decomposition of the three observed traits (days to emergence, days to the first flower, and days to maturity) into the functional traits corresponding to the phenological parameters of the WOFOST-GT2 model was carried out using the optimisation

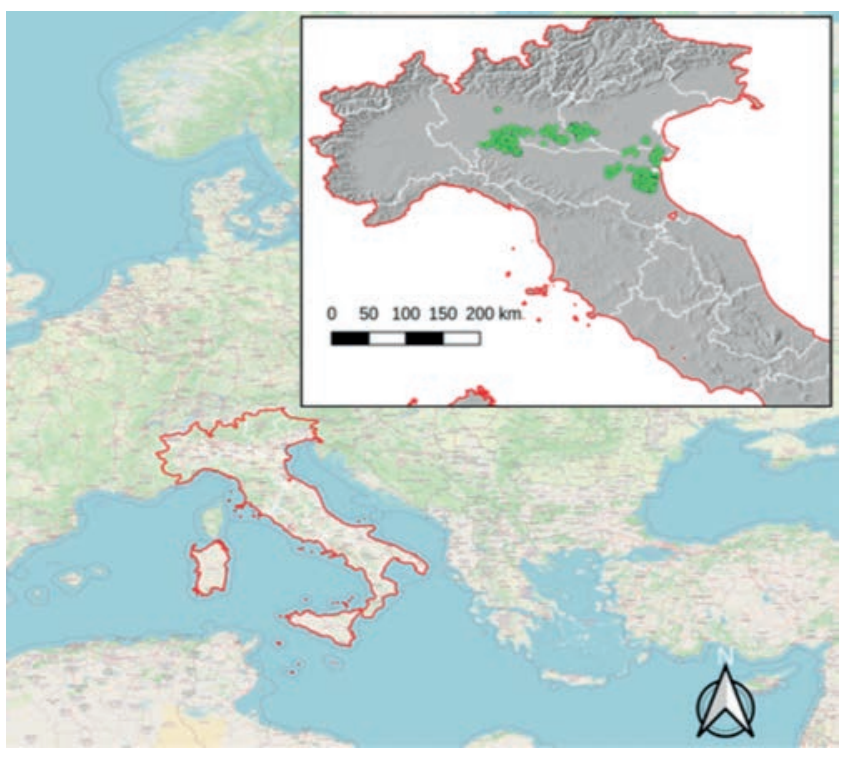

Figure 2. Sites where field data were collected. 
method of the bounded downhill simplex (Acutis and Confalonieri, 2006). In practice, the optimisation allowed deriving the cultivarspecific parameter values able to maximise the agreement between observed and simulated days to emergence, flowering, and maturity. The parameters for which the optimisations were run were base, optimum, and maximum temperature $\left({ }^{\circ} \mathrm{C}\right)$ and the thermal time thresholds $\left({ }^{\circ} \mathrm{C}\right.$-day) needed to reach emergence (GDDem), flowering (GDDflw), and maturity (GDDmat).

\section{Agro-climatic characterisation of the study area for cultivar recommendation}

After parameterising the crop model for field pea and retrieving cultivar-specific values for phenological parameters, we focused on the Emilia-Romagna region for the case study on cultivar recommendation.

By adopting the same approach proposed by Paleari et al. (2020), the study area was characterised for soil, climate, and management practices to derive homogeneous contexts. Information on soil texture from the regional service (https://geo.regione.emilia-romagna.it/geocatalogo/) was used to classify the soil as fine (clay content $>35 \%$ and sand content $<65 \%$ ), coarse (clay content $<17.5 \%$ and sand content $>65 \%$ ), or medium (all remaining soils) according to Al Majou et al. (2008). The variability observed in planting dates (Figure S1) led to identifying two sowing times, early ( $1^{\text {st }}$ of February) and late ( $1^{\text {st }}$ of April), as those representing the extremes of the main sowing window. Besides sowing time, no other sources of variability in management were considered, given that in the study area field, the pea is normally not irrigated, grown under unlimited conditions for nutrients, and fields are kept pest-, weed- and disease-free. Weather data from 2009 to 2018 were retrieved from the same weather database used to decompose complex traits. Weather data were used to calculate the agro-climatic index SAM (Synthetic AgroMeteorological indicator, Confalonieri et al., 2010) for each climate cell $\times$ sowing time combination, by considering an average crop cycle duration of 90 days and 70 days for, respectively, early and late sowings (Figure S2). From the soil and climate zonation intersection, 24 agro-climatic contexts were defined (12 for early sowings and 12 for late sowings; Figure 3).

\section{Ideotype design and cultivar recommendation}

Paleari et al. (2020) developed the methodology to identify the cultivar (or the cultivars) most suitable for each of the 24 agro-climatic contexts. This approach is based on the definition of contextspecific ideotypes by using crop modelling and SA techniques and on the evaluation of the similarity between the ideotypes - which represent a target combination of functional traits - and the phenotypic profiles (at functional trait level) of the available cultivars. The cultivar (or cultivars) more similar to the ideotype identified for a given context are assumed to be the one (or the ones) with the highest potential according to the objective function used to derive the ideotypes. In this case study, the traits considered are only those involved with phenological development, and the objective function is aimed at maximising both yield and yield stability.

The variance-based E-FAST (extended fourier amplitude sensitivity test) global SA method - as implemented in the software SIMLAB (Tarantola and Becker, 2016) - was used for sampling the parameter hyperspace to identify key traits for improving yield and yield stability and to define the ideotypes. The total number of parameter combinations was set to $1500(250 \times$ the number of parameters) according to Confalonieri et al. (2010a). Parameter distributions were derived from the results of the optimisationbased decomposition of complex traits performed on the 13 culti- vars. In particular, the Shapiro-Wilk test (Shapiro and Wilk, 1965) was first used to test normality. In the case of non-normality, the Kolmogorov-Smirnov test was used to identify the distribution that better fitted optimised parameter values.

After most relevant parameters for each of the 24 agro-climatic contexts were identified through SA, the 1500 parameter combinations - representing potential genotypes of interest - were ranked according to the objective function ( $\mathrm{Y}_{\text {index }}, \mathrm{Eq}$. 1) proposed by Ravasi et al. (2020) to account for both yield and yield stability:

$$
Y_{\text {index }}=\left[\left(\frac{Y_{i}}{Y_{\max }}\right) \cdot 0.7\right]+\left[\left(1-\frac{C V_{i}}{C V_{\max }}\right) \cdot 0.3\right]
$$

Where $Y_{i}$ and $C V_{i}$ are the mean and the coefficient of variation of yield values simulated with the $i$ th combination of parameters over the ten-year time frame considered in the analysis (i.e., from 2009 to 2018); $Y_{\max }$ and $C V_{\max }$ represent the maximum value of the metrics that are achieved among the 1500 combinations.

The mean of parameter values of the best $1 \%$ of combinations was used to define the ideotype profile for each of the 24 contexts.
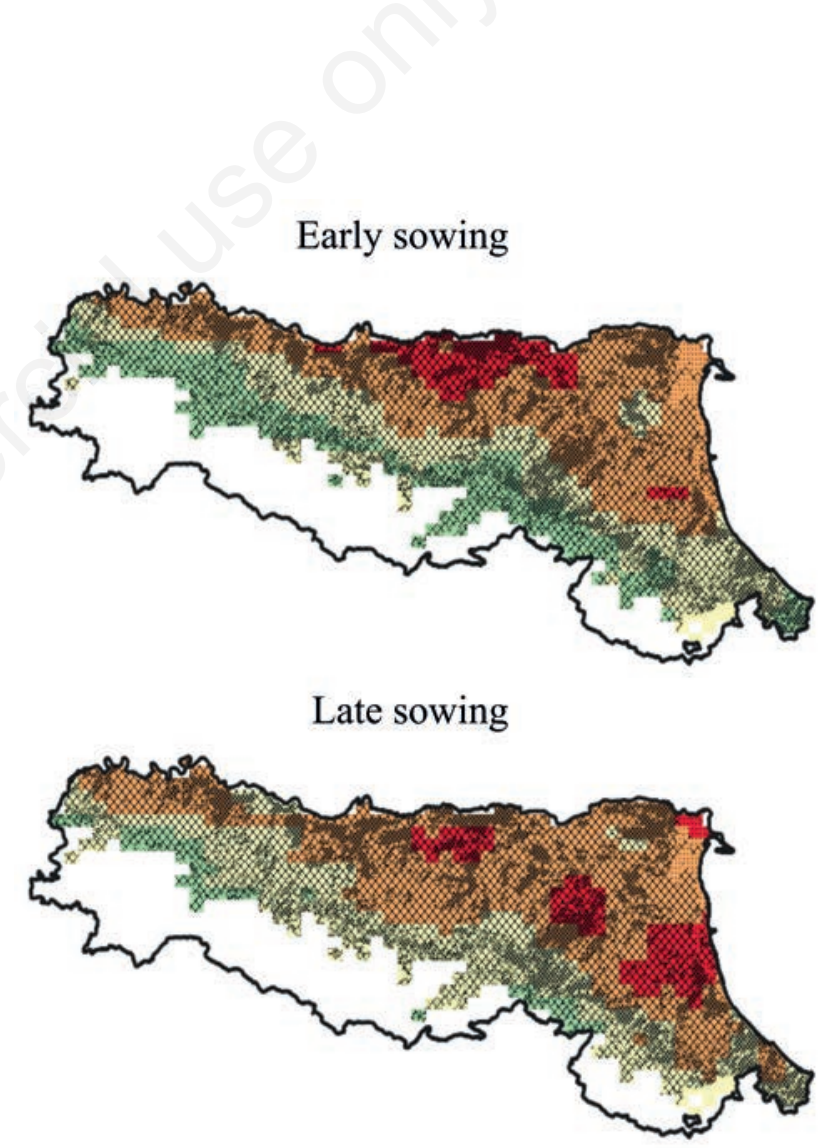

$\mathrm{SAM} \leq-0.35$

$-0.35<$ SAM $\leq-0.25$

$-0.25<\mathrm{SAM} \leq-0.15$

$\mathrm{SAM}>0.15$

Fine soil

Medium soil

Coarse soil

Figure 3. Characterisation of the study area according to the soil, climate, and management conditions. Soil class (Al Majou et al., 2008): fine (clay content $>35 \%$ and sand content $<65 \%$ ), coarse (clay content $<17.5 \%$ and sand content $>65 \%$ ), medium (all remaining soils). The Synthetic AgroMeteorological indicator (SAM; Confalonieri et al., 2010) is the average estimate of the decade 2009-2018. 
Following the methodology proposed by Paleari et al. (2020), the similarity between the ideotype profile and functional trait profiles of the available pea cultivars was quantified - for each context - using the weighted Euclidean distance as proposed by Carvalho et al. (2002). This approach is based on the definition of the optimum range, the optimum trait value, and the relative importance of each trait, which were derived as the range of variation of the trait explored among the best $1 \%$ of parameter combinations, the value of the trait defined for the ideotype, and the relevance of the trait as quantified by the SA index, respectively. The cultivar (among the 13 available) with the functional trait profile closer to the ideotype profile was considered as the recommended one. Further details on this approach for cultivar recommendation are available in Paleari et al. (2020).

\section{Results and discussion}

\section{Species-specific model parameterisation for field pea}

Results of the species-specific calibration of WOFOST-GT2 for field pea (Table S3) show that the model successfully reproduced key dynamics involved with crop growth. EF values were 0.78 and 0.88 for aboveground biomass and LAI, respectively, and the values of the other agreement metrics confirmed the satisfying model behaviour without relevant systematic over- or under-estimations [coefficient of residual mass $(\mathrm{CRM})<|0.2|]$. These results can be considered as satisfactory according to the thresholds for the metrics proposed, e.g., by Chung et al. (1999), Bellocchi et al. (2002), Moriasi et al. (2007), although RRMSE for aboveground biomass was slightly poorer $(42.08 \%)$. The good performance achieved for aboveground biomass and LAI was confirmed by the values of the agreement metrics for the biomass of the different plant organs, with EF always higher than 0.56, RRMSE never exceeding 49\%, and CRM always lower than $|0.1|$. Among plant organs, the highest accuracy was obtained for pod biomass $(\mathrm{EF}=0.86$; $\mathrm{RRMSE}=43.51 \%$ and $\mathrm{CRM}=-0.2)$. Regardless of the simulated variable, the $\mathrm{R}^{2}$ of the linear regression between observed and simulated data was always higher than 0.62 , with the best value achieved for LAI $\left(\mathrm{R}^{2}=0.99\right)$.

Results achieved for the validation datasets were even better for aboveground biomass, with RRMSE, EF, and $\mathrm{R}^{2}$ equal to $27.01 \%, 0.85$, and 0.91 , respectively. Results for the biomass of the different plant organs were instead similar to those achieved during calibration, with EF ranging from 0.52 for stem biomass to 0.86 for pod biomass. In general, a slight overestimation was observed during validation regardless of the variable analysed, although CRM was always lower than $|0.19|$.

Considering total aboveground biomass, the values of the agreement metrics are in line with those reported for pea by Ravasi et al. (2020) and by Coucheney et al. (2015) in studies where the STICS model was used.

\section{Cultivar-specific decomposition of complex phenologi- cal traits through optimisation}

Results of the cultivar-specific optimisation of phenological parameters were also satisfactory (Table 1). Average discrepancies between measured and simulated days from sowing to emergence, flowering, and maturity were minimal, with the overall MAE (calculated for all cultivars and phenological traits) equal to 2.34 days. Mean MAE within cultivars ranged from 1.49 days for cv. Amalfi to 4.69 days for cv. Lambado. Considering MAE, best results were achieved for the traits days to emergence and days to flowering (mean MAE calculated for all cultivars were equal to 2.03 and 2.11 days, respectively), whereas results for days to maturity were lightly poorer (MAE=2.89 days). The satisfying results were confirmed by the values achieved for the other metrics, with overall RRMSE and $\mathrm{EF}$ equal to $8.9 \%$ and 0.53 . However, despite the good agreement achieved in absolute terms (number of days) for days to emergence, this trait was the one for which the poorest results were obtained for the other metrics. Model performance was less satisfactory for this trait, with mean RRMSE for all cultivars equal to $16.44 \%$, whereas it was $4.76 \%$ for days to maturity and $5.61 \%$ for days to flowering (5.61). Among the cultivars, the best results were achieved for the group including cv. Boston and Wav1337 and for the cv. Provenzale, whereas the poorest for cv. Lambado.

Table 1. Results of the cultivar-specific calibration conducted for phenology.

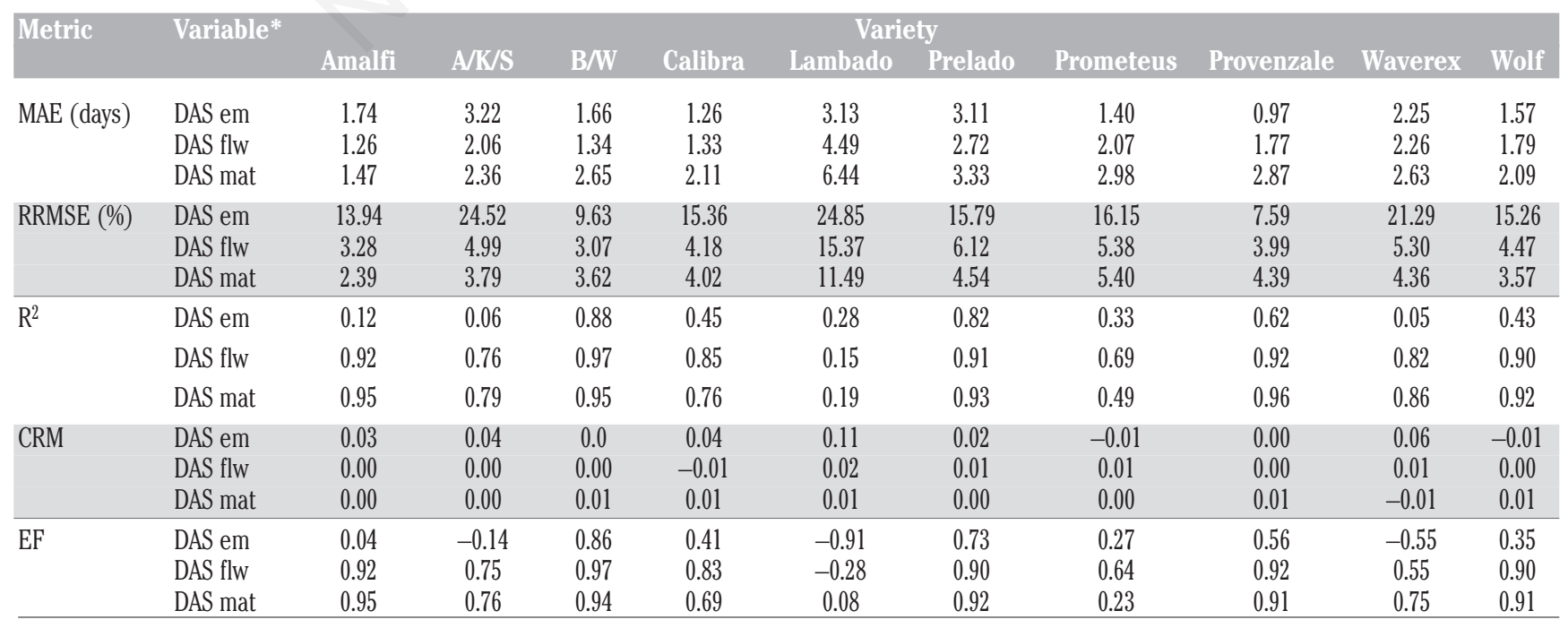

*DAS em, days from sowing to emergence; DAS flw, days from sowing to flowering; DAS mat, days from sowing to maturity; MAE, mean absolute error; RRMSE, relative root mean square error; R², coefficient of determination; CRM, coefficient of residual mass; EF, Nash-Sutcliffe modelling efficiency. 
The CRM highlighted a light model underestimation for days to emergence (mean CRM calculated for all cultivars was equal to 0.03 ), whereas no systematic under- or over-estimation was observed for days to flowering and days to maturity. The negative EF values achieved for the cultivars Lambado and Waverex and for the group including the cultivars Agami, Keysee and Starlight were likely due to the low variability observed for days to emergence among the different environments (Figure S3): this made the mean of observations an acceptable predictor for single observations (Criss and Winston, 2008).

The performances quantified by the metrics presented in Table 1 were achieved with cultivar-specific sets of parameter values that will be considered, hereafter, as functional traits, i.e., the results of the decomposition of the complex traits days to emergence, days to flowering, and days to maturity. The distribution of these functional traits is shown in Figure 4, whereas the parameters of their statistical distributions (always normal according to the ShapiroWilk's test) are reported in Table S4. The profile of each variety in terms of functional traits is available in Table 2.

Concerning the functional trait base temperature for development, values ranged from $2.9^{\circ} \mathrm{C}$ (group of cultivars including Boston and Wav1337) to $6^{\circ} \mathrm{C}$ (cv. Waverex), with an average value of $4^{\circ} \mathrm{C}$. Although the cultivars used in this study refer to germplasm highly adapted to the growing conditions of Northern Italy, these values are in line with those reported by other authors. For example, Olivier and Annandale (1998) reported literature values for different green pea cultivars ranging from $0^{\circ} \mathrm{C}$ to $5.5^{\circ} \mathrm{C}$, with a mean value of $3.4^{\circ} \mathrm{C}$. Similar values were indicated by Bourgeois et al. (2000) for four pea cultivars. An average base temperature of $4^{\circ} \mathrm{C}$ was also reported by Raveneau et al. (2011) for shoot elongation of three pea cultivars. Concerning optimal temperature for development, the mean value obtained for the thirteen cultivars was equal to $24.3^{\circ} \mathrm{C}$, with values for the different cultivars ranging from $18.9^{\circ} \mathrm{C}$ (Lambado) to $26.9^{\circ} \mathrm{C}$ (the group including Boston and Wav1337). In contrast, the mean value of maximum temperature was equal to $33.6^{\circ} \mathrm{C}$, with Waverex showing the lower values $\left(30.6^{\circ} \mathrm{C}\right)$. Provenzale the highest $\left(37.2^{\circ} \mathrm{C}\right)$, in line with the values indicated for this trait by other authors (mean of the values reported equal to $22.8^{\circ} \mathrm{C}$ and $34.6^{\circ} \mathrm{C}$ for optimum and maximum temperature, respectively; Olivier and Annandale, 1998; Guilioni et al., 2003; Vocanson and Jeuffroy, 2008). For the three functional traits involved with growing degree days accumulation, the comparison with literature values is hampered by different cardinal temperatures used for their calculation. For instance, considering thermal requirements to reach emergence, the average value obtained in this study $\left(125^{\circ} \mathrm{C}\right.$-days; range: $89-147^{\circ} \mathrm{C}$-days $)$ is slightly higher than values available in the literature (close to $100^{\circ} \mathrm{C}$-days; Olivier and Annandale, 1998), likely because of different base temperature used for thermal time accumulation.

Concerning the variability observed in trait values among cultivars, GDDem (Figure 4A), GDDflw (Figure 4B), and base temperature (Figure 4D) showed the highest heterogeneity (coefficient of variation equal to $16.9 \%, 22.8 \%$, and $21.3 \%$, respectively). This is partly due to a single value markedly different from the mean $\left(5.96^{\circ} \mathrm{C}\right.$, cultivar Waverex) for base temperature. Less variability was instead observed for GDDmat (Figure 4C), optimum (Figure $4 \mathrm{E}$ ), and maximum (Figure 4F) temperature for development, with a coefficient of variation equal to $11 \%, 9.5 \%$, and $6.8 \%$, respectively.

\section{Context-specific definition of ideotypes based on func- tional phenological traits}

Results of the SA (Figure S4) highlighted the key role of GDDflw for both early and late sowings, with this parameter explaining most of the variability in $\mathrm{Y}_{\text {index }}$ regardless of the conditions explored $(59.1 \%$ and $69.4 \%$ on average, for early and late sowings, respectively). In the case of early sowings, the optimal temperature for development also played an important role, explaining, on average, $22.2 \%$ of the $\mathrm{Y}_{\text {index }}$ variability. This value decreased to $12.6 \%$ in the case of late sowings, highlighting how thermal adaptation is crucial in early spring. The same considerations applied to base temperature for development, which explained on average $7.1 \%$ of the variability in $\mathrm{Y}_{\text {index }}$ for early sowings and slightly less than 5\% in the case of late ones. GDDem and GDDmat were never relevant for yield and yield stability, explaining less than $4 \%$ of the variability in the target output.

The ideotypes defined for each of the 24 agro-climatic contexts were mainly characterised by changes in thermal time requirements from emergence to flowering and base temperature (Figure S5). The variability in the agro-climatic conditions did not affect the ideotypes structure, with differences among context-specific ideotypes mainly regarding the intensity of the variation suggested

Table 2. Characterisation of the pea cultivars in terms of functional phenological traits.

\begin{tabular}{|c|c|c|c|c|c|c|c|c|c|c|}
\hline & & & & & & & iety & & & \\
\hline & Amalfi & $\mathrm{A} / \mathrm{K} / \mathrm{S}$ & $B / W$ & Calibra & Lambado & Prelado & Prometeus & Provenzale & Waverex & Wolf \\
\hline $\begin{array}{l}\text { Growing degree days from } \\
\text { sowing to emergence } \\
\left({ }^{\circ} \mathrm{C} \text {-days }\right)\end{array}$ & 119 & 113 & 145 & 142 & 100 & 89 & 141 & 147 & 110 & 139 \\
\hline $\begin{array}{l}\text { Growing degree days from } \\
\text { emergence to flowering } \\
\left({ }^{\circ} \mathrm{C} \text {-days }\right)\end{array}$ & 405 & 486 & 307 & 562 & 392 & 285 & 577 & 547 & 442 & 500 \\
\hline $\begin{array}{l}\text { Growing degree days from } \\
\text { flowering to maturity } \\
\left({ }^{\circ} \mathrm{C} \text {-days }\right)\end{array}$ & 442 & 441 & 427 & 367 & 397 & 481 & 380 & 459 & 334 & 394 \\
\hline $\begin{array}{l}\text { Base temperature } \\
\text { for development }\left({ }^{\circ} \mathrm{C}\right)\end{array}$ & 4.2 & 3.6 & 2.9 & 3.9 & 4.0 & 4.5 & 4.3 & 3.0 & 6.0 & 4.0 \\
\hline $\begin{array}{l}\text { Optimum temperature } \\
\text { for development }\left({ }^{\circ} \mathrm{C}\right)\end{array}$ & 24.5 & 25.9 & 26.9 & 23.2 & 18.9 & 24.1 & 23.5 & 26.0 & 26.4 & 23.7 \\
\hline $\begin{array}{l}\text { Maximum temperature } \\
\text { for development }\left({ }^{\circ} \mathrm{C}\right)\end{array}$ & 30.6 & 35.3 & 31.8 & 35.0 & 32.7 & 32.5 & 36.1 & 37.2 & 30.6 & 34.1 \\
\hline
\end{tabular}


as compared to current cultivars rather than in its direction (increase or decrease compared to current cultivars). The increase in GDDflw for the ideotypes as compared to the current cultivars (represented by the mean of the distribution, Table S4) was close to $25 \%$ regardless of the conditions explored in terms of climate, soil, and sowing time. For GDDem, the ideotypes showed on average lower thermal time requirements than current cultivars, especially in the case of late sowings $(-5.8 \%$ instead of $-3.1 \%$ of early sowings). However, early sowings highlighted a more considerable variability (standard deviation of the relative change was equal to $2.4 \%$ and $0.7 \%$ for early and late sowings, respectively). In the case of GDDmat, the increase in trait values for the ideotypes was very low, i.e., less than $5 \%$ for both sowing windows. A reduction in base temperature for development was a key feature of the ideotypes, with an average reduction equal to $-12.7 \%$ (early sowing) and $-19.4 \%$ (late sowing). Again, more significant heterogeneity across environments was achieved for early sowings: the standard deviations were equal to $6.9 \%$, whereas it was $1.5 \%$ for late sowings. Variation for optimal and maximum temperature was much lower (less than 10\%) regardless of the agro-climatic conditions explored, as highlighted by the small variability observed (standard deviation less than $0.5 \%$ in both cases).

\section{Model-aided cultivar recommendation}

Figures 5 and 6 show the rankings of the thirteen cultivars for each of the 24 agro-climatic contexts for, respectively, early and late sowings. The cultivar with the lowest similarity index is the most similar to the ideotype defined for the same context and, therefore, it is the one that is recommended for that context. Results clearly highlighted the three cultivars belonging to the group A/K/S (i.e., cv. Agami, Keysee, Starlight; Table S2) as the most suitable according to the conditions explored in the study area. They turned out to be the best choice for all the agro-climatic areas and for both early (Figure 5) and late sowings (Figure 6). Their functional phenotypic profile for traits involved with phenological development (Table 2) is the most similar to that of the ideotypes defined for the different contexts, especially for the traits with the largest impact on yield and yield stability. The similarity index weights indeed the contribution of the single traits using their sensitivity metrics (E-FAST total order effect; Figure S4).

Cultivars Amalfi and Wolf also resulted particularly suitable for the conditions explored in the study area, especially for early (Wolf) and late sowings (Amalfi). Wolf was indeed identified as the best cultivar in one case out of twelve in the case of early sowings (Figure 5B) and as a second choice (i.e., the difference in sim-
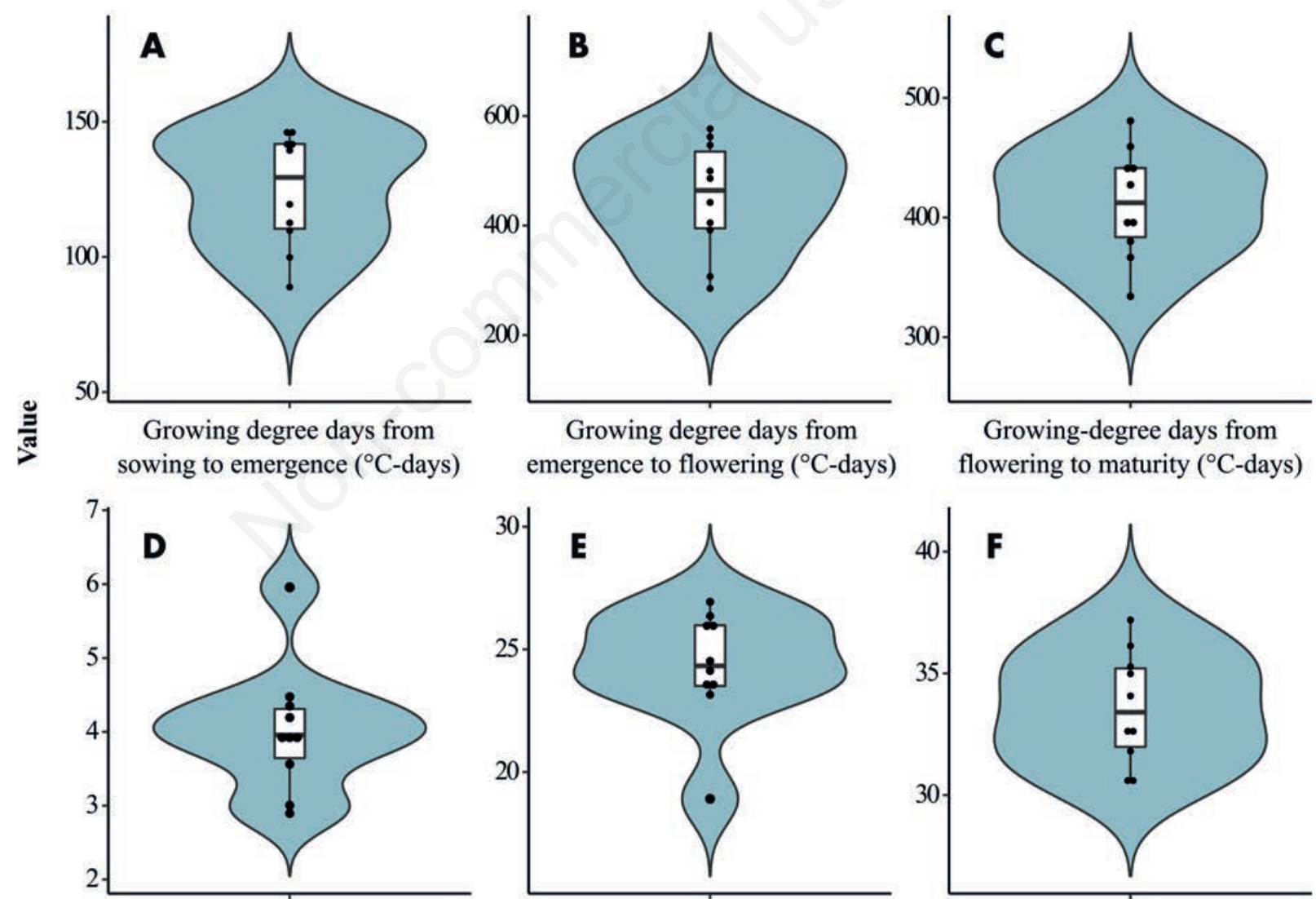

Base temperature for development $\left({ }^{\circ} \mathrm{C}\right)$
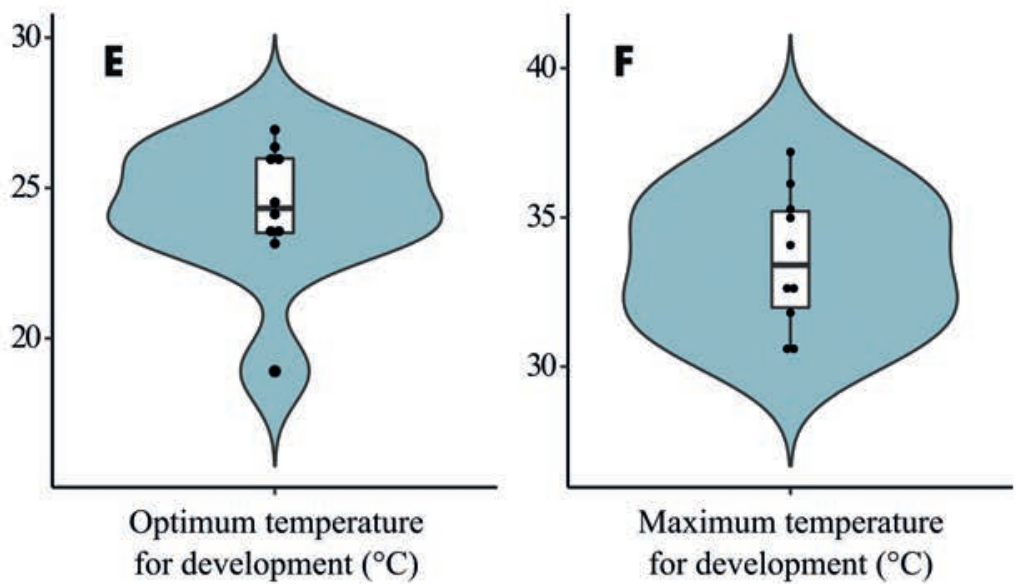

Variable

Figure 4. Violin plots of model parameters representing functional phenological traits, obtained via model-based decomposition of observed days to emergence, days to flowering, and days to maturity. 

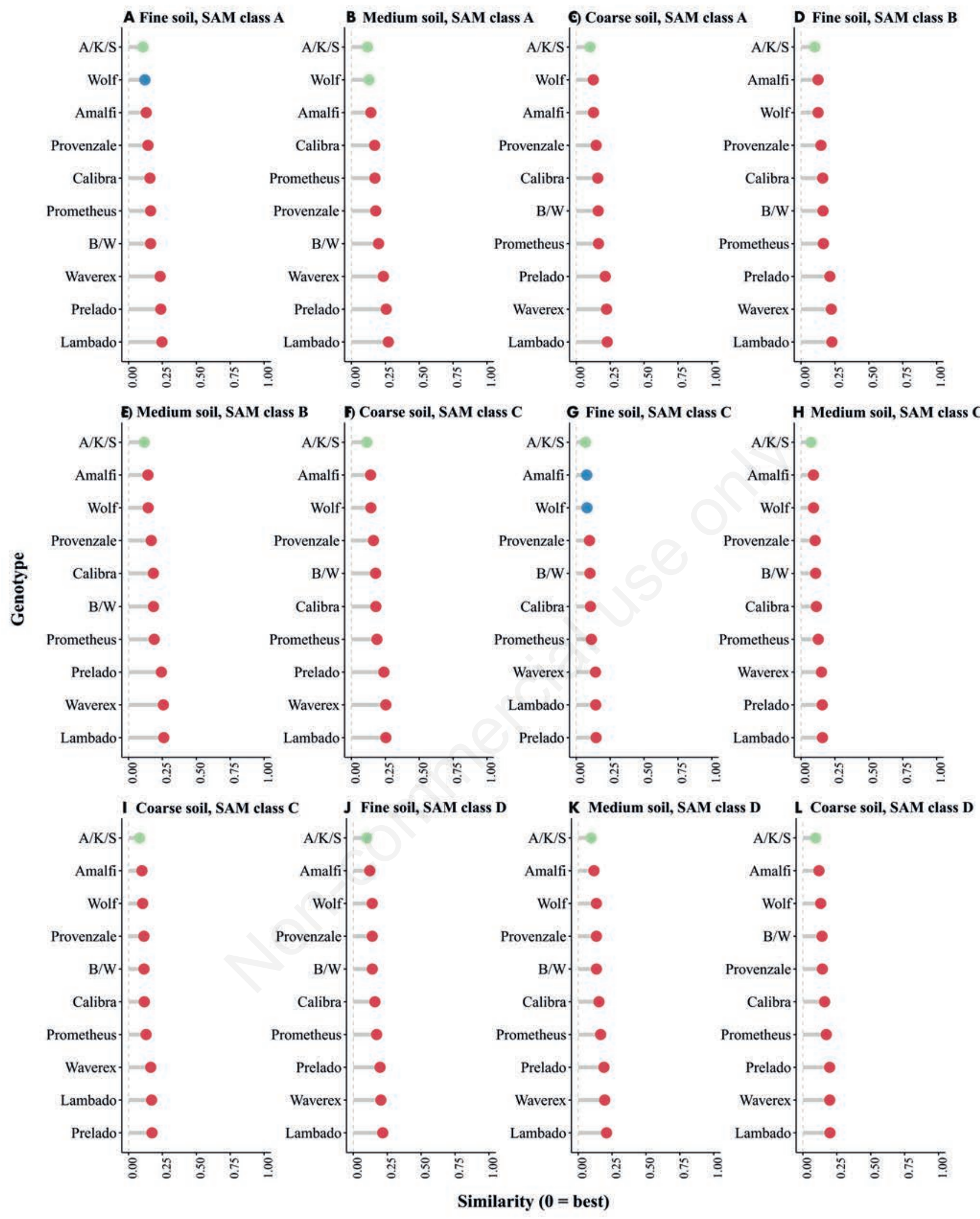

Figure 5. Cultivars ranked according to their similarity to the ideotype defined for each agro-climatic context in the case of early sowings. Green: varieties recommendable; blue: second-choice varieties; red: varieties less suitable (i.e., the difference in similarity index, respectively, lower than $10 \%$ compared to the most similar to the ideotype, between $10 \%$ and $20 \%$, and larger than $20 \%$ ). SAM class: $\mathrm{A}: \mathrm{SAM} \leq-0.35 ; \mathrm{B}:-0.35<\mathrm{SAM} \leq-0.25 ; \mathrm{C}:-0.25<\mathrm{SAM} \leq-0.15 ; \mathrm{D}: \mathrm{SAM}>-0.15$. 


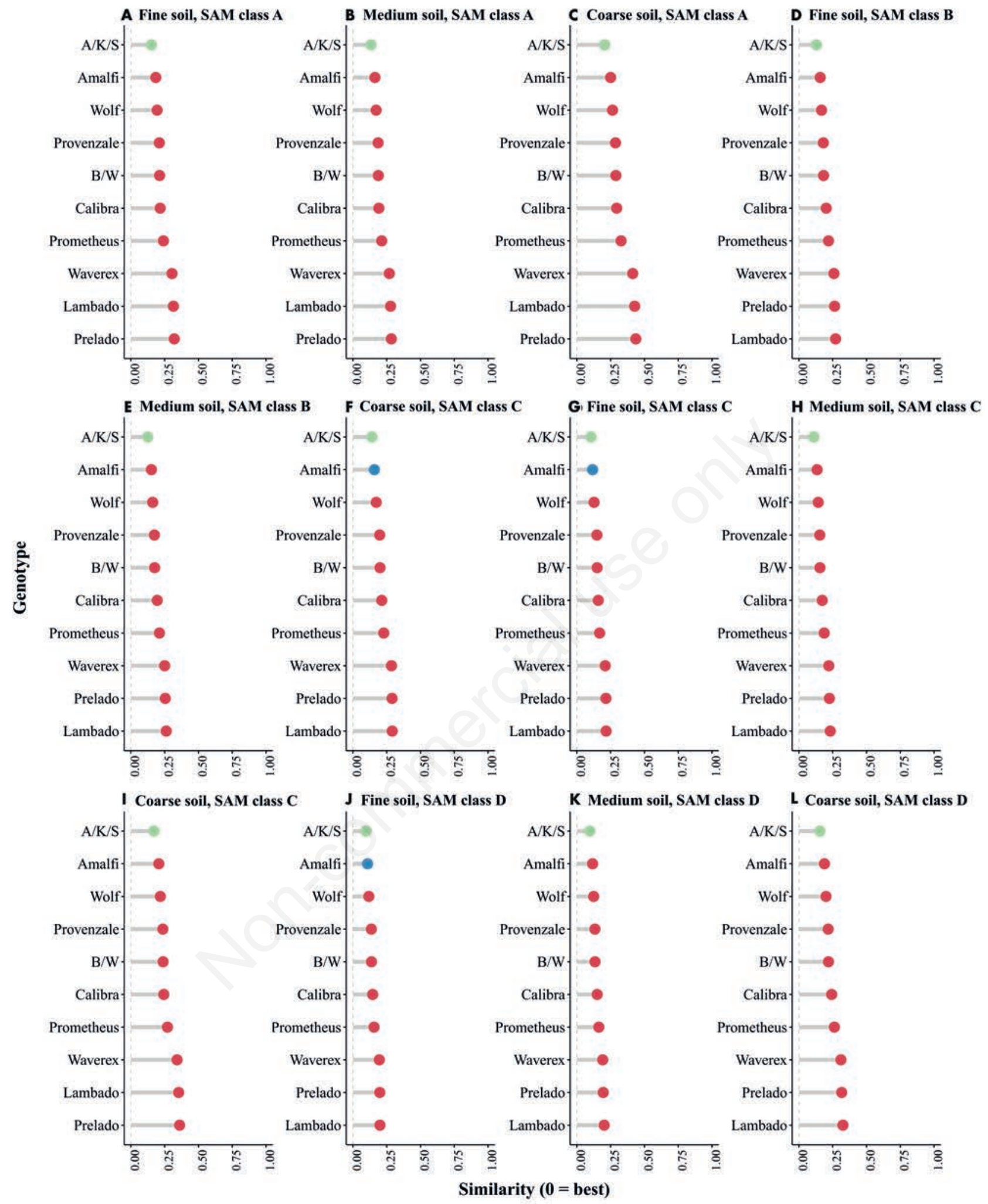

Figure 6. Cultivars ranked according to their similarity to the ideotype defined for each agro-climatic context in the case of late sowings. Green: varieties recommendable; blue: second-choice varieties; red: varieties less suitable (i.e., the difference in similarity index, respectively, lower than $10 \%$ compared to the most similar to the ideotype, between $10 \%$ and $20 \%$, and larger than $20 \%$ ). SAM class: A: SAM $\leq-0.35$; B: $-0.35<$ SAM $\leq-0.25 ; \mathrm{C}:-0.25<\mathrm{SAM} \leq-0.15$; D: $\mathrm{SAM}>-0.15$. 
ilarity index lower than $20 \%$ compared to the best cultivar) in two cases (Figure 5A and G). Amalfi was instead identified as a second choice in four cases out of 24: one case for early sowing (Figure $5 \mathrm{G}$ ) and three cases for late sowings (Figure 5F, G, and J). Wolf is probably better suited to early sowings due to larger thermal time requirements to reach flowering than Amalfi and lower base temperature for development (Table 2). These results are in line with the fact that Wolf is one of the most adopted cultivars in Northern Italy (Table S2) and that, together with Amalfi and Starlight, is among the cultivars recommended by the agronomic services in the study area (Emilia-Romagna region).

However, more quantitative validation of these results - e.g., by using data from multi-environment trials aimed at variety evaluation - is not feasible, because in this case study, we focused only on phenology without considering other traits (e.g., canopy structure, quality-related aspects, resistance to diseases) that can markedly affect the productivity and the value of products and, therefore, that play a key role for cultivar recommendation. The objective of this study was indeed to present a proof of concept on how crop modelling can successfully use data routinely collected under operational farming conditions (mainly dealing with complex traits) to derive cultivar profiles at the level of functional traits, which, in turn, are used to analyse cultivar similarities with context-specific ideotypes to support cultivar recommendation. This study uses a reverse-modelling approach to decompose complex traits in functional ones, which is particularly important for deriving phenotypic traits that are hard to estimate experimentally on large germplasms (Martre et al., 2015). The method we propose in this study extends previous approaches for cultivar recommendation in which the phenotypic characterisation was solely based on dedicated field trials (Jeuffroy et al., 2014; Casadebaig et al., 2016; Paleari et al., 2020). This increases the applicability of this family of approaches for cultivar recommendation by considering traits that are difficult to measure or whose estimate is costly or time-consuming.

\section{Conclusions}

We showed how reverse-modelling could successfully be used to derive phenotypic profiles of multiple cultivars at the level of functional traits, which are usually hard to quantify experimentally, with the ultimate goal of supporting cultivar recommendation via comparison of these profiles with those of context-specific ideotypes. The capability of crop models to explore a wide range of climate, soil, and management conditions while reproducing $\mathrm{G} \times \mathrm{E} \times \mathrm{M}$ interactions allows indeed to identify the best cultivar(s) for specific agro-climatic contexts with high spatial granularity. Furthermore, the approach presented in this study extends available methodologies for model-aided cultivar recommendation, using data referring to complex traits easy to measure under operational farming conditions - like, e.g., date of occurrence of major phenological stages - to derive the values of functional traits. Therefore, this approach can be considered particularly promising for increasing the applicability of model-aided cultivar recommendation under operational conditions. It does not require dedicated experimental activities targeting the direct profiling of available cultivars at the level of functional traits.

Despite the study's limits, which considers only traits involved with phenology, it represents proof of how data are easy to collect (e.g., by technical assistance services in operational farming contexts) can be successfully used to optimise cropping systems man- agement using advanced simulation techniques. Future developments will focus on applying and evaluating the same methodology for traits related to product quality, which is routinely measured by the processed pea industry when the row material is committed to the processing plant (e.g., tenderness and sugar content in case of a green pea). Traits involved with product quality play indeed a relevant role in defining the price of raw materials and the destination of the processed products and are often largely affected by $\mathrm{G} \times \mathrm{E} \times \mathrm{M}$ interactions. This makes a careful cultivar choice a key step in the production chain.

\section{References}

Acutis M, Confalonieri R, 2006. Optimization algorithms for calibrating cropping systems simulation models. A case study with simplex-derived methods integrated in the WARM simulation environment. Ital. J. Agrometeorol. 3:26-34.

Al Majou H, Bruand A, Duval O, Le Bas C, Vautier A, 2008. Prediction of soil water retention properties after stratification by combining texture, bulk density and the type of horizon. Soil Use Manag. 24:383-91.

Allen RG, Pereira LS, Raes D, Smith M, Ab W, 1998. Crop evapotranspiration - Guidelines for computing crop water requirements. Irrigation and drainage paper 56. Food and Agriculture Organization, Rome, Italy.

Annicchiarico P, 2002. Genotype x Environment Interactions Challenges and Opportunities for Plant Breeding and Cultivar Recommendations, FAO plant production and protection paper - 174. Food and Agriculture Organization, Rome, Italy.

Bellocchi G, Acutis M, Fila G, Donatelli M, 2002. An indicator of solar radiation model performance based on a fuzzy expert system. Agron. J. 94:1222-33.

Boote KJ, Prasad V, Allen LH, Singh P, Jones JW, 2018. Modeling sensitivity of grain yield to elevated temperature in the DSSAT crop models for peanut, soybean, dry bean, chickpea, sorghum, and millet. Eur. J. Agron. 100:99-109.

Bourgeois G, Jenni S, Laurence H, Roy G, Tremblay N, 2000. Improving the prediction of processing pea maturity based on the growing-degree day approach. Hortic. Sci. 35:611-4.

Carvalho CGP, Cruz CD, Viana JMS, Silva DJH, 2002. Selection based on distances from ideotype. Crop. Breed. Appl. Biotechnol. 2:171-8.

Casadebaig P, Mestries E, Debaeke P, 2016. A model-based approach to assist variety evaluation in sunflower crop. Eur. J. Agron. 81:92-105.

Chung SW, Gasman PW, Kramer LA, Williams JR, Gu R, 1999. Validation of EPIC for two watersheds in Southwest Iowa. J. Environ. Qual. 28:971-9.

Cola G, Mariani L, Maghradze D, Failla O, 2020. Changes in thermal resources and limitations for Georgian viticulture. Aust. J. Grape Wine Res. 26:29-40.

Confalonieri R, Bellocchi G, Bregaglio S, Donatelli M, Acutis M, 2010a. Comparison of sensitivity analysis techniques: A case study with the rice model WARM. Ecol. Model. 221:1897-906.

Confalonieri R, Bregaglio S, Acutis M, 2010b. A proposal of an indicator for quantifying model robustness based on the relationship between variability of errors and of explored conditions. Ecol. Model. 221:960-4.

Coucheney E, Buis S, Launay M, Constantin J, Mary B, García de Cortázar-Atauri I, Ripoche D, Beaudoin N, Ruget F, Andrianarisoa KS, Le Bas C, Justes E, Léonard J, 2015. 
Accuracy, robustness and behavior of the STICS soil-crop model for plant, water and nitrogen outputs: Evaluation over a wide range of agro-environmental conditions in France. Environ. Model. Softw. 64:177-90.

Criss RE, Winston WE, 2008. Do Nash values have value? Discussion and alternate proposals. Hydrol. Process. 22:27235 .

Guilioni L, Wéry J, Lecoeur J, 2003. High temperature and water deficit may reduce seed number in field pea purely by decreasing plant growth rate. Funct. Plant Biol. 30:1151-64.

Hammer GL, Chapman S, Van Oosterom E, Podlich DW, 2005. Trait physiology and crop modelling as a framework to link phenotypic complexity to underlying genetic systems. Aust. J. Agric. Res. 56:947-60.

Hammer GL, Kropff MJ, Sinclair TR, Porter JR, 2002. Future contributions of crop modelling - From heuristics and supporting decision making to understanding genetic regulation and aiding crop improvement. Eur. J. Agron. 18:15-31.

Jeuffroy MH, Casadebaig P, Debaeke P, Loyce C, Meynard JM, 2014. Agronomic model uses to predict cultivar performance in various environments and cropping systems. A review. Agron. Sustain. Dev. 34:121-37.

Jeuffroy MH, Vocanson A, Roger-Estrade J, Meynard JM, 2012. The use of models at field and farm levels for the ex ante assessment of new pea genotypes. Eur. J. Agron. 42:68-78.

Jørgensen SE, Kamp-Nielsen L, Christensen T, Windolf-Nielsen J, Westergaard B, 1986. Validation of a prognosis based upon a eutrophication model. Scope and Limit in the Application of Ecological Models to Environmental Management. Ecol. Model. 32:165-82.

Lecomte C, Prost L, Cerf M, Meynard JM, 2010. Basis for designing a tool to evaluate new cultivars. Agron. Sustain. Dev. 30:667-77.

Luquet D, Dingkuhn M, Kim H, Tambour L, Clement-Vidal A, 2006. EcoMeristem, a model of morphogenesis and competition among sinks in rice. 1 . Concept, validation and sensitivity analysis. Funct. Plant Biol. 33:309-23.

Mariani L, Cola G, Ferrante A, Martinetti L, Bulgari R, 2016. Space and time variability of heating requirements for greenhouse tomato production in the Euro-Mediterranean area. Sci. Total Environ. 562:834-44.

Mariani L, Parisi SG, Cola G, Failla O, 2012. Climate change in Europe and effects on thermal resources for crops. Int. J. Biometeorol. 56:1123-34.

Martre P, Quilot-Turion B, Luquet D, Memmah MMOS, Chenu K, Debaeke P, 2015. Model-assisted phenotyping and ideotype design. Crop Physiol. Appl. Genet. Improv. Agron. Second Ed. 349-73.

Meier U, 2001. Growth stages of mono- and dicotyledonous plants, Second. Ed. BBCH Monograph. Federal Biological Research Centre for Agriculture and Forestry.

Messina CD, Technow F, Tang T, Gho C, Cooper M, 2018. Leveraging biological insight and environmental variation to improve phenotypic prediction: Integrating crop growth models (CGM) with whole genome prediction (WGP). Eur. J. Agron. 100:151-62.

Moriasi D, Arnold J, Van Liew M, Bingner R, Harmel R, Veith T, 2007. Model evaluation guidelines for systematic quantifica- tion of accuracy in watershed simulations. Trans. ASABE 50:885-900

Nash JE, Sutcliffe JV, 1970. River flow forecasting through conceptual models part I - A discussion of principles. J. Hydrol. 10:282-90.

NOAA, 2020a. National Oceanic and Atmospheric Administration. Available from: https://data.noaa.gov/dataset /dataset/global-surface-summary-of-the-day-gsod/

NOAA, 2020b. National Oceanic and Atmospheric Administration. Available from: https://tgftp.nws.noaa.gov/ data/observations/metar/stations/ Accessed: 9 September 2021.

NOAA, 2020c. National Oceanic and Atmospheric Administration. Available from: https://tgftp.nws.noaa. gov/SL.us008001/DF.an/DC.sflnd/DS.synop/ Accessed: 9 September 2021.

Olivier FC, Annandale JG, 1998. Thermal time requirements for the development of green pea (Pisum sativum L.). Field. Crop. Res. 56:301-7.

Onogi A, Watanabe M, Mochizuki T, Hayashi T, Nakagawa H, Hasegawa T, Iwata, H, 2016. Toward integration of genomic selection with crop modelling: the development of an integrated approach to predicting rice heading dates. Theor. Appl. Genet. 129:805-17.

Paleari L, Vesely FM, Ravasi RA, Movedi E, Tartarini S, Invernizzi M, Confalonieri R, 2020. Analysis of the similarity between in silico ideotypes and phenotypic profiles to support cultivar recommendation - a case study on Phaseolus vulgaris L. Agronomy 10:1733.

Ravasi RA, Paleari L, Vesely FM, Movedi E, Thoelke W, Confalonieri R, 2020. Ideotype definition to adapt legumes to climate change: A case study for field pea in Northern Italy. Agric. For. Meteorol. 291:10881.

Raveneau MP, Coste F, Moreau-Valancogne P, Lejeune-Hénaut I, Durr C, 2011. Pea and bean germination and seedling responses to temperature and water potential. Seed Sci. Res. 21:20513 .

Shapiro SS, Wilk MB, 1965. An analysis of variance test for normality (complete samples). Biometrika 52:591.

Stella T, Frasso N, Negrini G, Bregaglio S, Cappelli G, Acutis M, Confalonieri R, 2014. Model simplification and development via reuse, sensitivity analysis and composition: A case study in crop modelling. Environ. Model. Softw. 59:44-58.

Tarantola, S, Becker, W, 2016. SIMLAB software for uncertainty and sensitivity analysis. In: Ghanem, R, Higdon, D, Owhadi, H (Eds.), Handbook of uncertainty quantification. Springer International Publishing, Cham, pp. 1-21.

USGS, 2020. USGS document. Available from: https://webgis.wr.usgs.gov/globalgis/gtopo30/gtopo30.htm Accessed: 9 September 2021.

van Keulen H, Wolf J, 1986. Modelling of agricultural production: weather, soils and crops. In: Simulation Monographs. Pudoc, Wageningen, The Netherlands, pp. 479.

Violle C, Navas ML, Vile D, Kazakou E, Fortunel C, Hummel I, Garnier E, 2007. Let the concept of trait be functional! Oikos. 116:882-92.

Vocanson A, Jeuffroy MH, 2008. Agronomic performance of different pea cultivars under various sowing periods and contrasting soil structures. Agron. J. 100:748-59. 